\title{
Long-Term Treatment of Tamoxifen and Raloxifene Alleviates Dystrophic Phenotype and Enhances Muscle Functions of FKRP Dystroglycanopathy
}

\author{
Bo Wu, ${ }^{*}$ Sapana N. Shah, ${ }^{*}$ Peijuan Lu, ${ }^{*}$ Lauren E. Bollinger, ${ }^{*}$ Anthony Blaeser, ${ }^{*}$ Susan Sparks, ${ }^{\dagger}$ Amy D. Harper, ${ }^{\dagger}$ and Qi L. Lu*
}

From the McColl-Lockwood Laboratory for Muscular Dystrophy Research* and the Clinical Genetics/Department of Pediatrics, ${ }^{\dagger}$ Levine Children's Hospital, Carolinas Medical Center, Charlotte, North Carolina

\author{
Accepted for publication \\ December 19, 2017. \\ Address correspondence to \\ Qi L. Lu, M.D., Ph.D., or \\ Bo Wu, Ph.D., McColl-Lockwood \\ Laboratory for Muscular \\ Dystrophy Research, Neuromus- \\ cular/ALS Center, Department of \\ Neurology, Carolinas Medical \\ Center, 1000 Blythe Blvd, \\ Charlotte, NC 28231. E-mail: \\ qi.lu@carolinashealthcare.org or \\ bo.wu@carolinashealthcare.org.
}

\begin{abstract}
The third most common form of limb-girdle muscular dystrophies is caused by mutations of the Fukutinrelated protein (FKRP) gene, with no effective therapy available. Selective estrogen receptor modulators, tamoxifen and raloxifene, have been widely used for human conditions for their anti-inflammatory, antifibrosis, prevention of bone loss, and muscle building effects (essential features for muscular dystrophy therapies). We evaluated therapeutic values of tamoxifen and raloxifene in FKRPP448L mutant mouse with severe dystrophic phenotype. The mice were treated with the drugs for 1 year through daily gavage. We demonstrate that tamoxifen and raloxifene significantly ameliorated the disease progression. The improvement includes increase in grip force production, extended running time and distance in treadmill test, and enhancement in cardiac and respiratory functions. Significant reduction in muscle pathology includes diminished fibrosis and fiber degeneration. Tamoxifen and raloxifene also significantly mitigated bone loss. Tamoxifen, but not raloxifene, caused severe adverse effects on male reproductive organs. The results demonstrate that tamoxifen and raloxifene hold significant potential for treating FKRP-related muscular dystrophy and probably other muscular dystrophies. Sex-related differential effects of the drugs call for a careful consideration for the drug and dosage selection in male and female patient populations. (Am J Pathol 2018, 188: 1069-1080; https://doi.org/10.1016/j.ajpath.2017.12.011)
\end{abstract}

Dystroglycanopathy is one specific group of muscular dystrophies, characterized by lack or reduced levels of functionally glycosylated $\alpha$-dystroglycan $(\alpha$-DG) in bodywide tissues, especially in muscles. Mutations in the $\alpha$-DG gene itself and in 17 other genes, either confirmed or putative glycosyltransferases, have been identified as the causes of the glycosylation defect. Dystroglycanopathies caused by mutations in the Fukutin-related protein (FKRP) gene exhibit a wide spectrum of disease severity, from a milder form of limb-girdle muscular dystrophy 2I to severe congenital muscular dystrophy type 1C, Walker-Warburg syndrome, and muscle-eye-brain disease. ${ }^{1-3}$ The limbgirdle muscular dystrophy 2I affects all muscle types with stress-related fiber damage, followed by degeneration, inflammatory response, and regeneration. The continuous loss of muscle fibers and diminishing capacity of regeneration eventually lead to the loss of muscle volume, with increase in fibrotic and fat tissues, and the loss of function. Consequently, patients gradually lose mobility, with impairment and failure of respiratory and cardiac functions. Recently, the pathway of $O$-mannosylation of $\alpha$-DG and the function of FKRP as a ribitol-5-phosphate transferase have been delineated. ${ }^{4-6}$ However, clinic and therapeutic development to the FKRP-related dystroglycanopathies during the past 15 years have been largely limited to the genetic diagnosis and analyses of genotype-phenotype correlation. Clinically, no effective therapy is available.

Herein, we examined the effect of selective estrogen receptor modulators (SERMs) for their potential to treat dystroglycanopathies using FKRPP448L (P448L) mutant

Supported by the Carolinas Muscular Dystrophy Research Endowment at the Carolinas HealthCare Foundation.

Disclosures: None declared. 
mice containing the p.P448L mutation as the model system. SERMs act on estrogen receptors (ERs) and induce differential effects as either ER agonists or antagonists in a tissue-cell type specific manner. The wide presence of ER as either $\alpha$ or $\beta$ form at different levels and in variable proportion in nearly all tissues results in broad spectrum of estrogen effects on functions of nearly all systems. Thus, SERMs, by differentially altering ER $\alpha$ and ER $\beta$ actions and under the further modulation of cofactors, exhibit highly variable effect on different tissues. Many of those effects, including prevention of bone loss and antiinflammatory and fibrosis effects, have been explored for the treatment of various human diseases, from breast cancer to herpes simplex virus-1 infection, and for muscle repair and enhancement of muscle function. ${ }^{7-13}$ Many of the SERMs' known and potential therapeutic benefits, including reported stabilizing effect on biological membranes and inhibition of apoptosis, are perceived desirable for treating muscular dystrophies and have led to animal model trials of tamoxifen for Duchenne muscular dystrophy. ${ }^{14}$ The same study, however, described raloxifene as not efficacious, although data were not presented. ${ }^{14}$ Herein, we reported a multidosage long-term efficacy study of both tamoxifen and raloxifene in the $P 448 \mathrm{~L}$ mutant mice with moderate skeletal muscle myopathy and impaired respiratory functions. The $P 448 \mathrm{~L}$ mutation also causes severe congenital muscular dystrophy in the clinic. ${ }^{15}$ Our results demonstrate clear therapeutic values with both SERMs in reducing muscle pathology and improving skeletal muscle, cardiac muscle, and respiratory functions. Efficacy and adverse effects are evidently dose dependent and sex related. More important, mechanisms for the observed therapeutic effect are almost certainly non-disease specific; thus, a similar approach is likely applicable to other muscular dystrophies.

\section{Materials and Methods}

\section{Ethics Approval and Consent to Participate}

This study was approved by the Institutional Animal Care and Use Committee, Carolinas Medical Center (Charlotte, $\mathrm{NC})$.

\section{Animals, Drugs, and in Vivo Delivery Methods}

In each treatment group, $10 P 448 L$ or $C 57 B L / 6$ mice (five female and five male mice), aged 3 weeks, were used. The mice were randomly assigned to control and different treatment groups, with littermates split between control and treatment groups. $P 448 L$ mice have $c .1343 C>T$ point mutation of $F K R P$ gene, resulting in an amino acid change from proline to leucine at position $448 .{ }^{15} \mathrm{P} 448 \mathrm{~L}$ mice were orally administrated with 50 or $100 \mathrm{mg} / \mathrm{kg}$ raloxifene (Teva Pharmaceuticals, North Wales, PA) or 2,10 , or $50 \mathrm{mg} / \mathrm{kg}$ tamoxifen (Letco Medical, Decatur, AL). The control
P448L mice were gavaged with the same amount of saline. Mice were sacrificed at scheduled time points, and muscles and organs were weighted, snap frozen in liquid nitrogen-cooled isopentane, and stored at $-80^{\circ} \mathrm{C}$. Experiments were analyzed blind to treatment group.

\section{Histologic Analysis and Measurement of Serum Creatine Kinase and Other Components}

As described previously, ${ }^{16}$ sections $(6 \mu \mathrm{m}$ thick $)$ were stained with monoclonal antibody IIH6C4 (Millipore, Temecula, CA) and Alexa Fluor 594-labelled goat-antimouse IgM (Invitrogen, Eugene, OR) for detection of functionally glycosylated $\alpha$-DG; tissue endogenous Igs were detected with goat-anti-mouse Igs Alexa Fluor 594. Sections were stained with hematoxylin and eosin for histologic assessment of fiber size and centranucleation using the MetaMorph Basic Offline software version 7.7.0.0 (Molecular Devices LLC, Sunnyvale, CA). The percentages of fibrosis in diaphragm, heart, and biceps muscles were measured from Masson's trichrome staining (ImageJ software version 1.42; NIH, Bethesda, MD; http://imagej.nih. gov/ij). The level of serum components was determined by Charles Riverside Laboratories International (Wilmington, MA).

\section{Protein Extraction and Western Blot Analysis}

Total proteins were extracted from tibialis anterior muscles using TX-100 buffer $[1 \%$ Triton $\mathrm{X}-100,50 \mathrm{mmol} / \mathrm{L}$ Tris (pH 8.0), $150 \mathrm{mmol} / \mathrm{L} \mathrm{NaCl}$, and $0.1 \%$ SDS] supplemented with protease inhibitor cocktail (Roche, Mannheim, Germany). Samples were homogenized in TX-100 buffer, and the supernatants were collected by centrifugation at $16,000 \times g$ for 10 minutes. Protein concentration was determined by modified Lowry assay (Bio-Rad DC protein assay). The lysates were then loaded onto $4 \%$ to $20 \%$ Trisglycine gel (Invitrogen, Carlsbad, CA). The proteins were transferred to polyvinylidene difluoride membranes with constant ampere at $200 \mathrm{~mA}$ for 2 hours in cold room $\left(4^{\circ} \mathrm{C}\right)$. Polyvinylidene difluoride membranes were incubated with protein-free T20 blocking buffer (Pierce, Rockford, IL). The antibodies against $\alpha$-DG (IIH6C4) and $\alpha$-actin (Sigma, St. Louis, MO) were incubated in $20 \mathrm{mmol} / \mathrm{L}$ Tris ( $\mathrm{pH} \mathrm{7.4),}$ $150 \mathrm{mmol} / \mathrm{L} \mathrm{NaCl}$, and $0.1 \%$ Tween 20 at 1:2000 dilutions. $\alpha$-DG and $\alpha$-actin antibodies were detected by horseradish peroxidase-goat anti-mouse IgM (Invitrogen, Carlsbad, CA) and goat anti-rabbit IgG-horseradish peroxidase conjugate (Bio-Rad, Hercules, CA), respectively. Blots were developed with electrochemiluminescence (PerkinElmer, Waltham, MA), and the images were exposed and processed by an LAS-4000 imaging system (Fujifilm, Valhalla, NY). The intensity of the bands was measured and compared with that from normal muscle of $C 57 \mathrm{BL} / 6$ mice (ImageJ software). 


\section{Grip Strength and Treadmill Test}

Grip strength was assessed using a grip strength meter consisting of horizontal forelimb mesh and an angled hind limb mesh (Columbus Instruments, Columbus, $\mathrm{OH}$ ). Five successful forelimb and hind limb strength measurements within 2 minutes were recorded, and data were normalized to body weight $(\mathrm{BW})$. Treadmill test was performed on LE8700 treadmill (Panlab/Harvard Apparatus, Barcelona, Spain). Mice were acclimated with a 0 -degree plane for 5 minutes at a speed of $7 \mathrm{~cm} / \mathrm{second}$ on treadmill, then rested for another 10 minutes. After the acclimation and rest, mice were put back onto the treadmill, starting at $7 \mathrm{~cm} / \mathrm{second}$, with increasing speed of $1 \mathrm{~cm} / \mathrm{second}$ every 30 seconds. Maximum speed was $25 \mathrm{~cm} / \mathrm{second}$. A $0.2-\mathrm{mA}$ shock grid was used throughout the procedure. The test end points were mice exhaustion, as demonstrated by the animal remaining on the shock grid for 10 consecutive seconds without getting off or $50 \%$ on/off within 1-minute period.

\section{Plethysmography}

Mice were placed in a single chamber for 5 minutes' acclimation, and then respiratory parameters were recorded for 15 minutes in Vent4, a ventilation pump for four plethysmography (Emka Technologies, Falls Church, VA).

\section{Echocardiogram}

Echocardiogram was performed using the Bioscan SonixTablet Ultrasound System (Analogic Ultrasound, Peabody, MA). Detailed method was published by Blaeser et al. ${ }^{17}$

\section{Bone Density}

Femurs and tibias of mice were digitally $\mathrm{X}$ rayed on Portable Pixarray 100 (BioOptics Software, Tucson, AZ) $\mathrm{X}$-ray machine. Bone density was measured using ImageJ software. Same bones from age-matched normal C57BL/6 mice were used as controls.

\section{Statistical Analysis}

All of the results were expressed as means \pm SEM. The data were analyzed using one-way analysis of variance test for comparing tamoxifen- or raloxifene-treated groups, Pearson correlation coefficient test for dose dependence for tamoxifen- or raloxifene-treated groups, and two-tailed $t$-test for comparing individual treatments with saline group. $P \leq 0.05$ was considered as the level of significance for all statistical tests.

\section{Results}

One-Month Administration of 2 and $10 \mathrm{mg} / \mathrm{kg}$ Tamoxifen Significantly Improves Muscle Functions and Reduces Pathology

The initial evaluation was performed in 3-week-old P448L mutant mice. The mice were daily gavaged with tamoxifen and raloxifene for 1 month. All of the mice behaved without difference to the saline-treated control group. However, 10 $\mathrm{mg} / \mathrm{kg}$ tamoxifen treatment reduced BW significantly, with the reduction more profound in male mice than in female mice (Supplemental Figure S1, A-C). Tamoxifen treatments at 2 or $10 \mathrm{mg} / \mathrm{kg}$ significantly increased muscle strength of the hind limbs by grip strength measurement in both female and male groups, whereas no significance was observed with $50 \mathrm{mg} / \mathrm{kg}$ raloxifene (Supplemental Figure S1, D-F). Significant decrease in creatine kinase level was only observed in the group with $10 \mathrm{mg} / \mathrm{kg}$ tamoxifen. Serum tests for liver and kidney functions and histology of the organs were normal in all groups (data not shown) (Supplemental Figure S1G). One-month treatments of all cohorts did not significantly affect weights of all muscle tissues compared with saline controls (Supplemental Figure $\mathrm{S} 1, \mathrm{H}-\mathrm{K})$.

Treatments with both drugs reduced muscle pathology, with significant reduction in the numbers of degenerating fibers (Figure 1, A and B). Although groups of regenerating fibers were frequently observed in the muscles of saline control mice, such fibers were only occasionally identified in all of the skeletal muscles from the two tamoxifen treatment groups. Histology improvement was further supported by significant reduction of centranucleated fibers in all of the treatment groups, and dose dependently from approximately $40 \%, 17 \%$, and $7 \%$ in saline, $2 \mathrm{mg} / \mathrm{kg}$ tamoxifen, and $10 \mathrm{mg} / \mathrm{kg}$ tamoxifen groups, respectively. Raloxifene treatment resulted in moderate reduction in centranucleated fibers (approximately 20\%) (Figure 1, C and E). Furthermore, infiltration was decreased in the groups with 2 and $10 \mathrm{mg} / \mathrm{kg}$ tamoxifen, but not with the $50 \mathrm{mg} / \mathrm{kg}$ raloxifene treatment (Figure 1, D and E). The histologic improvements were especially obvious in the treated diaphragms, which experienced most rapid degeneration and heavy infiltration in control saline-treated mice (Figure 1E).

\section{One-Year Treatment of the SERMs Affects the Body Weight of Male and Female Mice Differentially}

One-year effects of the drugs with different dosages based on the 1-month results were next investigated. Three dosages, 2,10 , and $50 \mathrm{mg} / \mathrm{kg}$, of tamoxifen and two doses, 50 and $100 \mathrm{mg} / \mathrm{kg}$, of raloxifene were examined. All of the treatments started at the age of 3 weeks of P448L mutant mice with daily gavage. BW became lighter starting at approximately 10 days after treatments with all dosages of tamoxifen and raloxifene in a dose-dependent manner, and 


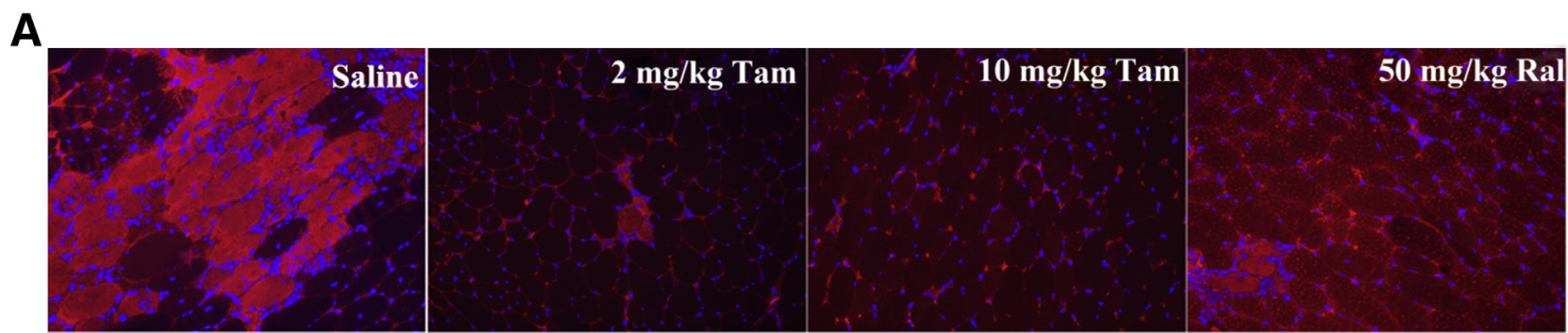

B

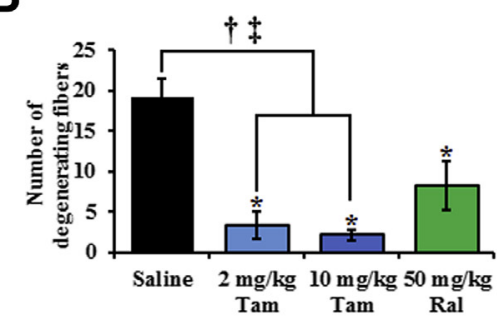

C

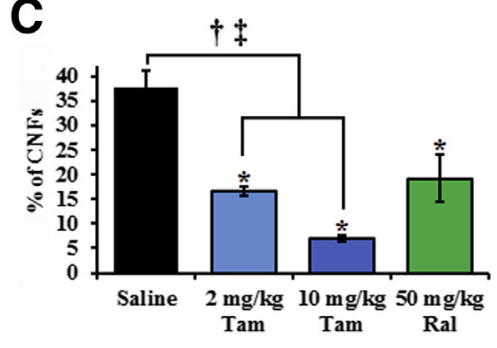

D

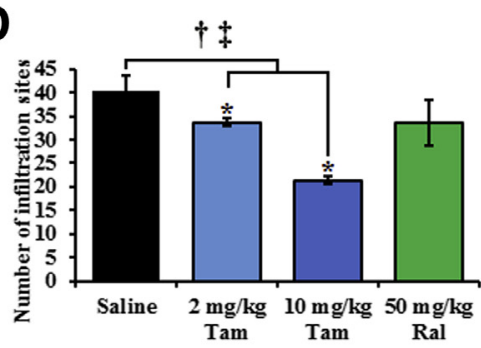

E

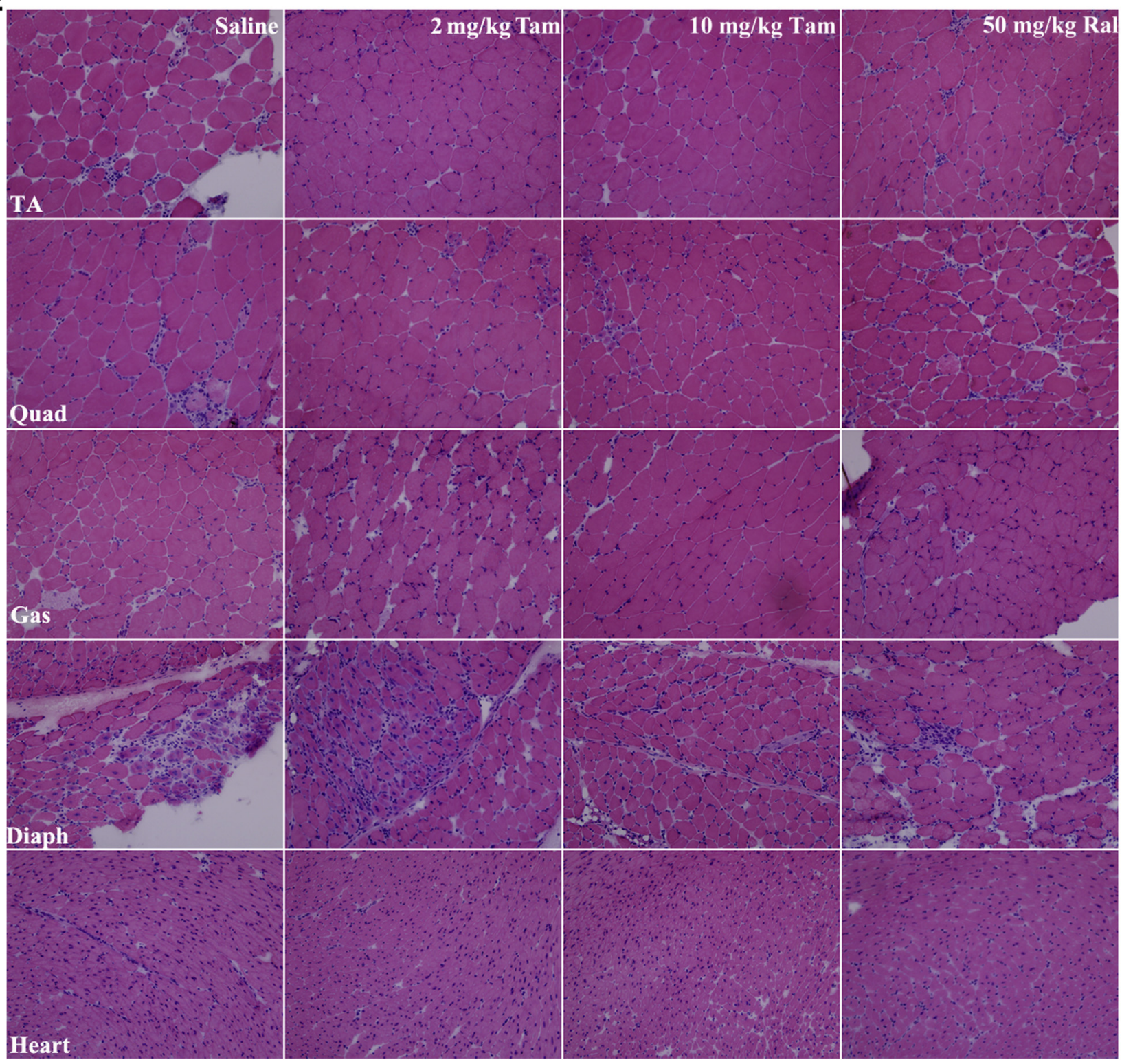


was significantly lower than the saline control group at the age of 1 year (Figure 2A). However, when male and female mice were analyzed separately, significance was only observed between the male-treated and control groups, but not between all of the female-treated and control groups (Figure 2, B and C).

\section{One-Year Treatment of the SERMs Dose Dependently Improves Skeletal Muscle Functions and Reduces Pathology}

One-year treatments of tamoxifen and raloxifene dose dependently improved grip strength of both forelimb and hind limb (Figure 2D). Interestingly, when the sex was analyzed separately, significant improvement was seen in tamoxifen-treated male groups, but not female groups. However, high-dose raloxifene treatment improved grip force in both male and female groups (Figure 2, E and F). Significant improvement in skeletal muscle function was also demonstrated by treadmill test with both tamoxifen and raloxifene treatments. Consistently, tamoxifen treatment also resulted in stronger enhancement (almost two times) in running ability of the male than that of female mice (Figure 2, G-I).

The enhancement in muscle functions was supported by reduction in limb muscle pathology. The control $P 448 L$ mice showed high variation in fiber size, the presence of groups of degenerating fibers, and focal inflammatory infiltrations. These dystrophic changes were greatly reduced in the muscles of the treated mice with the SERM treatments (Figure 3). Tamoxifen and raloxifene dose dependently reduced monocyte infiltration sites from 72.4 (saline groups) to $13.4,12.8$, and $9.8(2,10$, and $50 \mathrm{mg} / \mathrm{kg}$ tamoxifen, respectively), or to 52.5 and 15.4 (50 and $100 \mathrm{mg} / \mathrm{kg}$ raloxifene, respectively) (Figure $3, \mathrm{~A}$ and $\mathrm{B}$ ). Centranucleated fibers decreased from approximately $60.2 \%$ in saline-treated group to approximately $55.4 \%, 38.3 \%$, and $36 \%$ in tamoxifen groups and $55.4 \%$ and $50.2 \%$ in raloxifene groups from lower to higher dose, respectively, in tibialis anterior muscles (Figure 3, A and C). Small regenerating fibers also decreased significantly, and hypertrophic fibers almost disappeared in the muscles of 10 or $50 \mathrm{mg} / \mathrm{kg}$ tamoxifen- and 50 or $100 \mathrm{mg} / \mathrm{kg}$ raloxifene-treated mice. Accordingly, fiber sizes in the treated groups were normalized considerably compared with saline group (Figure 3, A and D). Furthermore, all treatment groups showed reduced serum creatine kinase levels significantly (Figure 3E). Consistently, Masson's trichrome staining demonstrated a dramatic reduction in collagen accumulation in the limb muscles from all of the treatment groups compared with the saline group (Figure 4, A-D and F). Reductions in muscle histology were similar in both sexes (Supplemental Figures S2, S3, and S4).

\section{One-Year Treatment of the SERMs Significantly Reduces Diaphragm Pathology and Improves Respiratory Functions}

The P448L mice showed progressive muscle degeneration and regeneration in the diaphragm, and this was associated with increasing amount of fibrosis and infiltration (Figure 3 and Figure 4, A and G). The treatment of both tamoxifen and raloxifene eliminated the focal infiltration and large areas of fiber necrosis (with more than five degenerating fibers in a cluster), and ameliorated infiltration and extents of central nucleation, although these pathologic hallmarks persisted. The size of the fibers was considerably more uniform, with fewer small fibers representing regeneration (Figure 3). Most significantly, the extent of fibrosis decreased dramatically in both sexes of mice treated with both drugs (Figure 4 and Supplemental Figure S4). The protection of diseased muscles from heavy wasting was clearly reflected by the increase in the mass of diaphragm, with significance identified in all tamoxifen-treated groups when compared with the control group (Figure 4G). The weight of diaphragm with raloxifene treatment was also increased, although it was statistically not significant. However, considering the significant decrease in fibrotic tissue within the treated diaphragm in comparison to controls, the protective effect of raloxifene treatments is also compelling. The apparently similar weight of diaphragm in the control mutant mice to C57 mice is consistent with the fact that the muscle fibers of mutant diaphragm were replaced with fibrotic and inflammatory components.

Respiratory function was evaluated by unrestrained whole-body plethysmography at the end of the study. The most significant deficiency in respiratory function of the $P 448 L$ mice is the prolonged inspiratory time, end-inspiratory pause (EIP), respiratory frequency, midexpiratory flow, shortened peak inspiratory flow, peak expiratory flow, and tidal and expired volumes when compared with normal C57 mice (Figure 5). Significant improvement was observed after both tamoxifen and raloxifene treatments compared with control mice. Specifically, raloxifene treatment dose dependently decreased inspiratory time with statistical significance (Figure 5A).

\footnotetext{
Figure 1 Effects of 1-year treatment of tamoxifen (Tam) and raloxifene (Ral) on muscle pathology. A: Detection of degenerating fibers (red stained) in tibialis anterior (TA) muscles by immunostaining with Alexa 594-conjugated goat anti-mouse Igs. B: The number of degenerating fibers in TA muscles. C: Percentages of centranucleated fibers (CNFs) in TA muscles. D: The number of infiltration sites (with $>10$ monocytes in one focal area) in TA muscles. E: Hematoxylin and eosin staining of TA, quadriceps (Quad), gastrocnemius (Gas), diaphragm (Diaph), and heart. P448L mice treated with saline only (saline); 2 and $10 \mathrm{mg} / \mathrm{kg} \mathrm{Tam}$; and $50 \mathrm{mg} / \mathrm{kg}$ Ral. Data are expressed as means \pm SEM (B-D). $n=10$ mice (5 female and 5 male; B-D). ${ }^{*} P<0.05$, two-tailed $t$-test for comparing individual treatment with saline group; ${ }^{\dagger} P<0.05$, one-way analysis of variance test for comparing multiple tamoxifen treatments with saline; ${ }^{\ddagger} P<0.05$, Pearson correlation coefficient test for tamoxifen's dose dependence.
} 
A

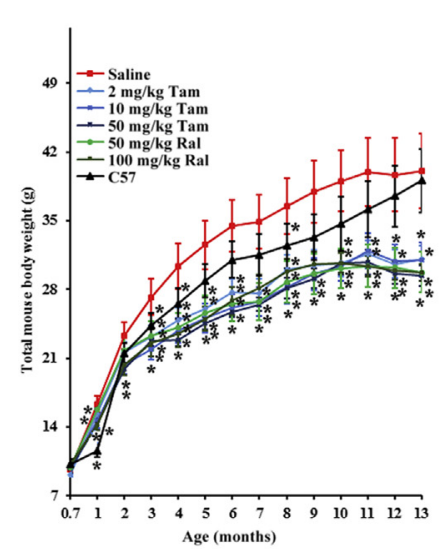

D

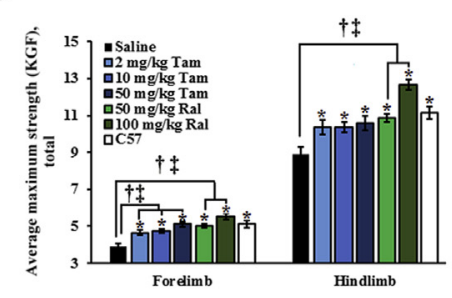

G

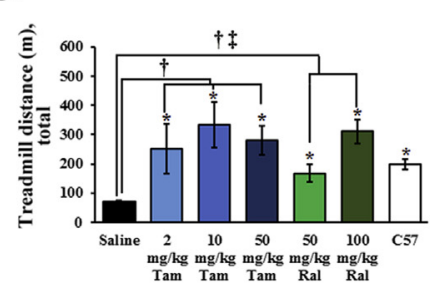

B

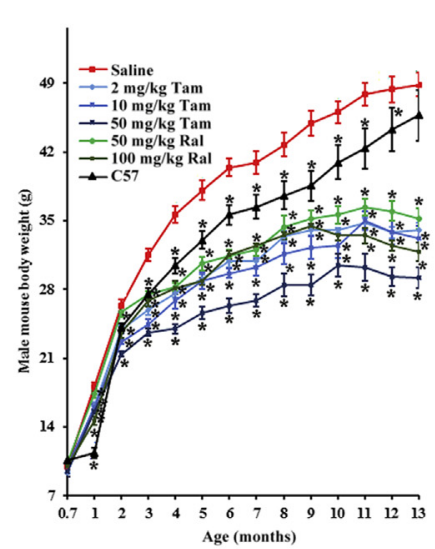

E

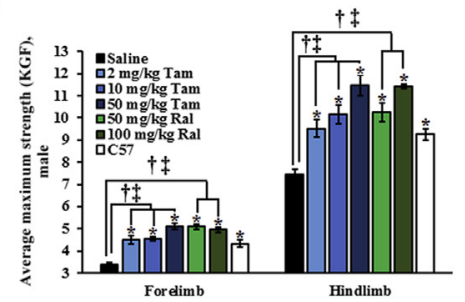

H

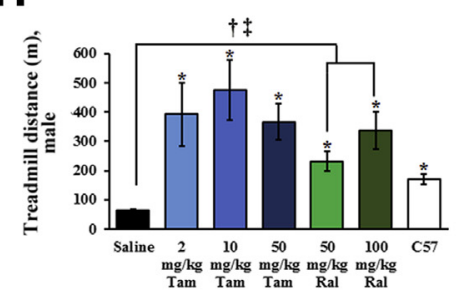

C

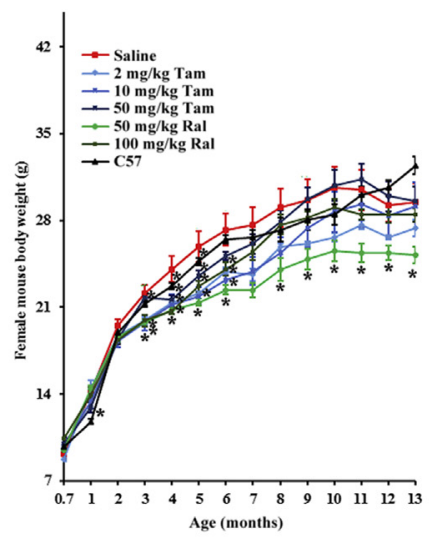

F

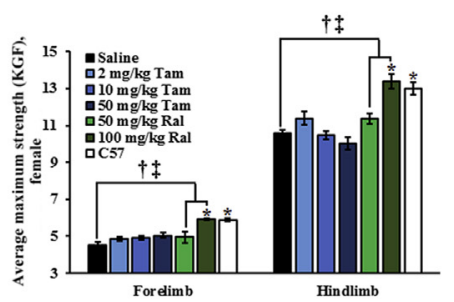

I

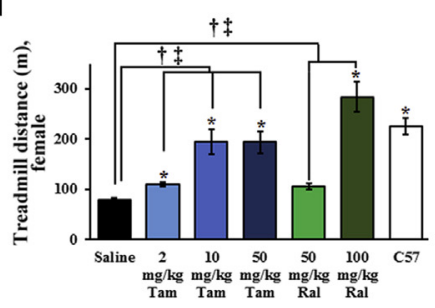

Figure 2 Effect of 1-year treatment of tamoxifen (Tam) and raloxifene (Ral) on body weight (BW) and skeletal muscle function. Curves of BW change in total (A), male (B), and female (C) mice during the 1-year treatments. BW change became significant 10 days after treatments. Grip strength measurement in total (D), male (E), and female (F) mice. Running distance measurement in total (G), male (H), and female (I) mice in treadmill test. Tamoxifen and raloxifene dose dependently significantly reduce male body weights compared with the same age of saline control group at all age points starting at 10 days after treatments, with $P \leq 0.05$ from one-way analysis of variance test and Pearson correlation coefficient test for tamoxifen's or raloxifene's dose dependence in B. P448L mice treated with saline only (saline); 2, 10, and $50 \mathrm{mg} / \mathrm{kg} \mathrm{Tam;} \mathrm{and} 50$ and $100 \mathrm{mg} / \mathrm{kg} \mathrm{Ral;}$ and untreated C57 mice (C57). Data are expressed as means $\pm \operatorname{SEM}(\mathbf{D}-\mathbf{I}) . n=10$ mice $(\mathbf{A}, \mathbf{D}$, and $\mathbf{G}) ; n=5$ male mice $(\mathbf{B}, \mathbf{E}$, and $\mathbf{H}) ; n=5$ female mice $(\mathbf{C}, \mathbf{F}$, and $\mathbf{I}) .{ }^{*} P<0.05$, two-tailed $t$-test for comparing individual treatment with saline group; ${ }^{\dagger} P<0.05$, one-way analysis of variance test for comparing multiple tamoxifen or raloxifene treatments with saline; ${ }^{\ddagger} P<0.05$, Pearson correlation coefficient test for tamoxifen's or raloxifene's dose dependence. KGF, kilogram force.

The other significant improvement was the reduction in EIP, respiratory frequency, and midexpiratory flow in all treated groups, reaching similar levels as observed in C57 mice (Figure 5, B-D). Both tamoxifen and raloxifene treatments, especially $50 \mathrm{mg} / \mathrm{kg}$ tamoxifen, significantly increased the peak inspiratory flow, peak expiratory flow, and tidal and expired volumes, achieving similar levels to that detected in C57 mice (Figure 5, E-H). No significant difference between female and male $P 448 L$ mice was identified (Supplemental Figure S5).

\section{One-Year Treatment of the SERMs Improves Cardiac Functions}

As reported previously, cardiac muscle of the $P 448 L$ mice $<6$ months of age showed only sparsely distributed narrow streak of fibrotic area, not obviously distinguishable from the wild-type heart. ${ }^{17}$ The fibrotic area increased in size and reached to approximately $2 \%$ in the mutant heart by the age of 1 year with Masson's trichrome staining (Figure 4). However, all of the treatments resulted in significantly reduced fibrotic area (Figure 4, A and E). Focal infiltration occasionally present in the control cardiac muscle became undetectable in all treated groups (Figure 3).

The treatments on cardiac function by ultrasound scanning were further investigated. Consistent with the mild pathologic changes, no significant difference between P448L mice and C57 mice at 1 year of age was detected in most parameters of the echocardiograph, including ejection fraction, stroke volume, and cardiac output (CO) (Supplemental Figure S6). The only significant difference is the faster heart rate in the $P 448 L$ mutant mice compared 


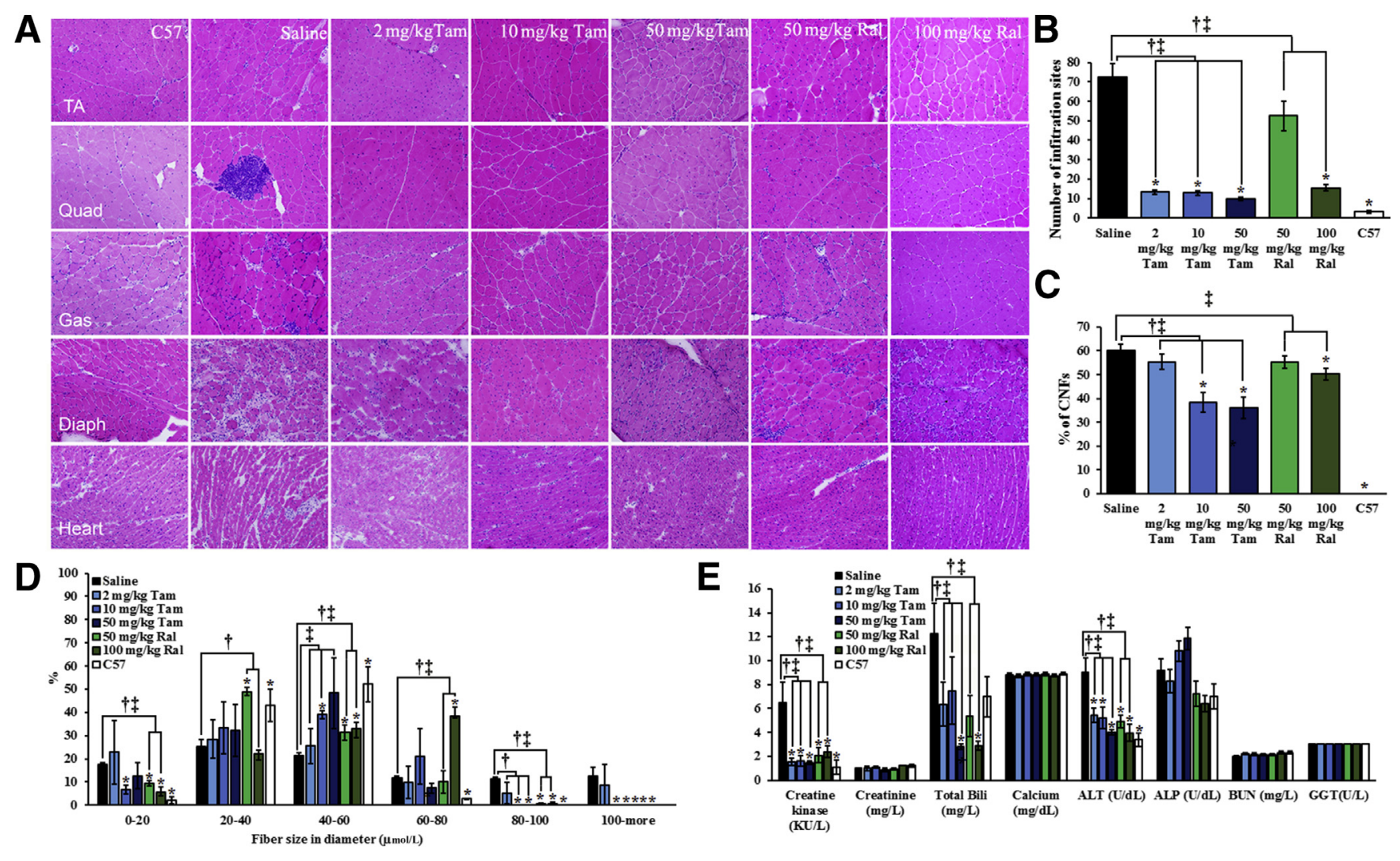

Figure 3 Effect of 1-year treatment of tamoxifen (Tam) and raloxifene (Ral) on muscle pathology and serum enzymes. A: Hematoxylin and eosin staining of tibialis anterior (TA), quadriceps (Quad), gastrocnemius (Gas), diaphragm (Diaph), and heart. B: The number of infiltration sites (with >10 monocytes in one focal area) in TA muscles. C: Percentages of centranucleated fibers (CNFs) in TA muscles. D: Distribution of fiber sizes of TA muscles in diameter ( $x$ axis). E: Serum testing. Creatine kinase, creatinine, total bilirubin (Total Bili), calcium, alanine transaminase (ALT), alkaline phosphatase (ALP), blood urea nitrogen (BUN), and $\gamma$-glutamyltransferase (GGT) are shown; the number in the $y$ axis represents unit value as described on the $x$ axis. P448L mice treated with saline only (saline); 2 , 10, and $50 \mathrm{mg} / \mathrm{kg} \mathrm{Tam}$; and 50 and $100 \mathrm{mg} / \mathrm{kg} \mathrm{Ral}$; and untreated $C 57$ mice (C57). Data are expressed as means \pm SEM (B-E). $n=10 \mathrm{mice}$ (5 female and 5 male; B-E). ${ }^{\star} P<0.05$, two-tailed $t$-test for comparing individual treatment with saline group; ${ }^{\dagger} P<0.05$, one-way analysis of variance test for comparing multiple tamoxifen or raloxifene treatments with saline; ${ }^{\ddagger} P<0.05$, Pearson correlation coefficient test for tamoxifen’s or raloxifene's dose dependence.

with C57 mice (Supplemental Figure S6J). One-year treatment of three doses of tamoxifen dose dependently and high-dose $100 \mathrm{mg} / \mathrm{kg}$ raloxifene decreased heart rates (Supplemental Figure S6J). However, when male and female mice were analyzed separately, tamoxifen dose dependently increased stroke volume in female $P 448 \mathrm{~L}$ mice, but decreased stroke volume and $\mathrm{CO}$ in male mice (Supplemental Figure S6, E, F, H, and J). However, this decrease was linked to the dramatic reduction in the $\mathrm{BW}$ of male mutant mice (Figure 2B). Therefore, when adjusted with $\mathrm{BW}$, both $50 \mathrm{mg} / \mathrm{kg}$ tamoxifen and $100 \mathrm{mg} / \mathrm{kg}$ raloxifene groups showed a significantly increased $\mathrm{CO}$ index in the male groups (Supplemental Figure S6). Raloxifene at $50 \mathrm{mg} / \mathrm{kg}$ showed reduced stroke volume and $\mathrm{CO}$ in male $P 448 L$ mice, but no difference in CO index was detected against the control group (Supplemental Figure S6).

\section{Effect of Tamoxifen and Raloxifene Treatment on Bone Density and Glycosylation of $\alpha$-Dystroglycan}

The bone density of 1-month and 1-year treated mice of all groups was examined with X-ray analysis. No significant difference was detected between all treated groups and the saline control group 1 month after treatment (Supplemental Figure S7A). However, 1-year treatment with both tamoxifen and raloxifene improved the bone density of both tibia and femur in both sexes (Figure 6, A-F). Neither raloxifene nor tamoxifen increased the number of positive fibers and levels of functionally glycosylated $\alpha$-DG by immunostaining and Western blot analysis, respectively, after the 1-month and 1-year treatments (Supplemental Figures S7 and S8).

\section{Effect of Tamoxifen and Raloxifene Treatment on Reproductive and Other Organs}

Treatment of tamoxifen and raloxifene had differential impact on reproductive organ sizes. Tamoxifen dose dependently reduced the mass of the male reproductive organs. After 1 year of treatment with the dose of $50 \mathrm{mg} / \mathrm{kg}$, the masses of vas deferens and testicles were less than one third of normal size, and seminal vesicles were hardly visible. Tamoxifen had less severe effect on prostate at any dose, and only the highest dose caused significant reduction in penis mass. In contrast, 1 year of raloxifene treatment 
A
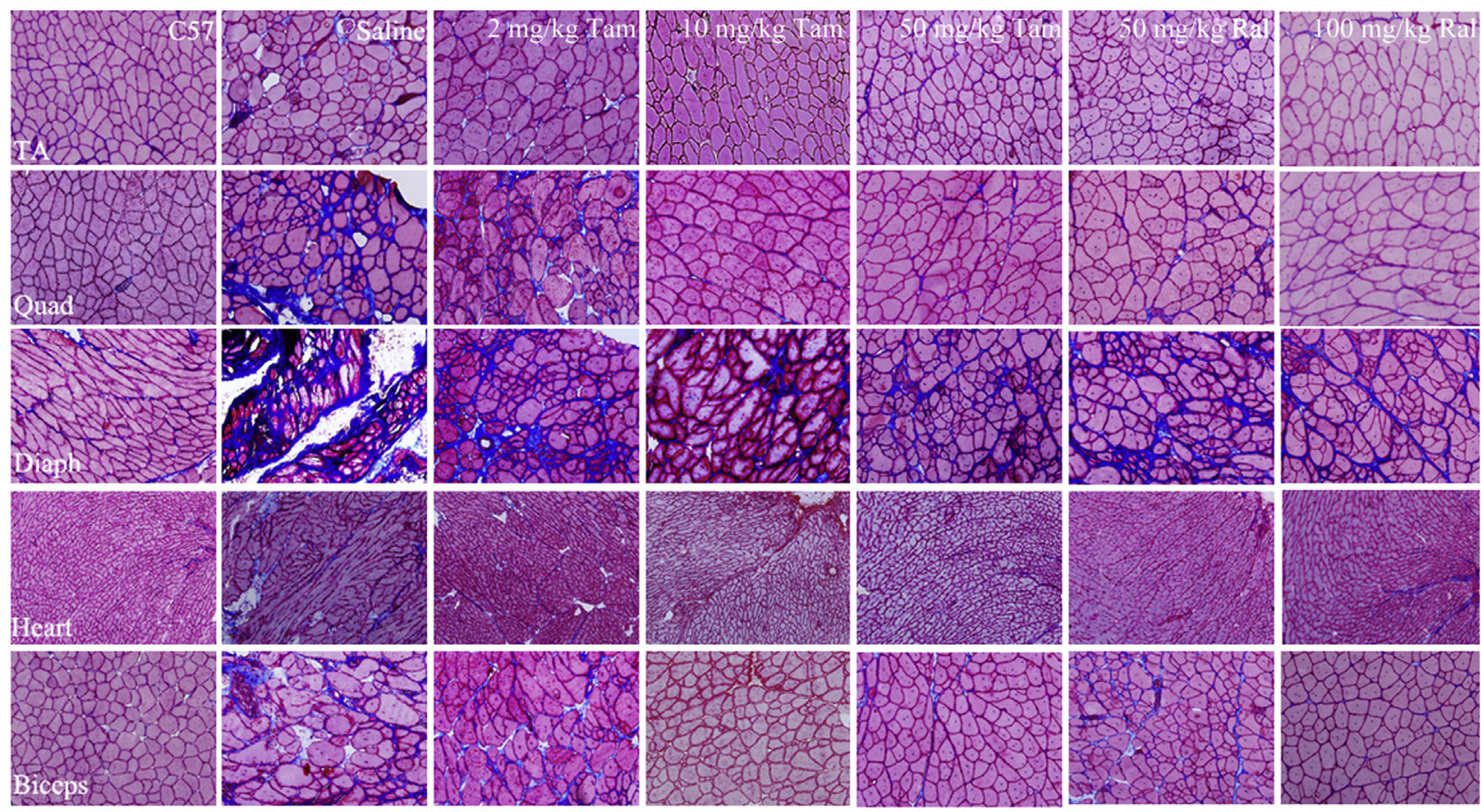

B

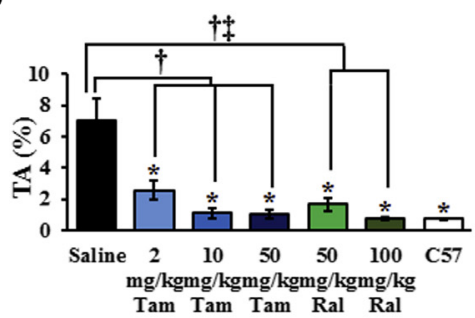

E

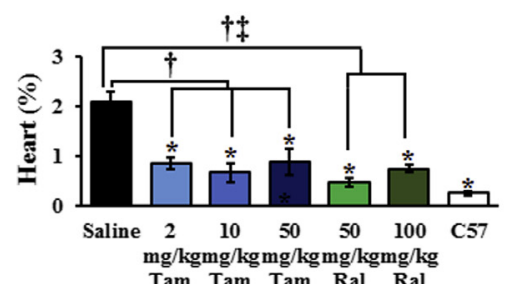

C

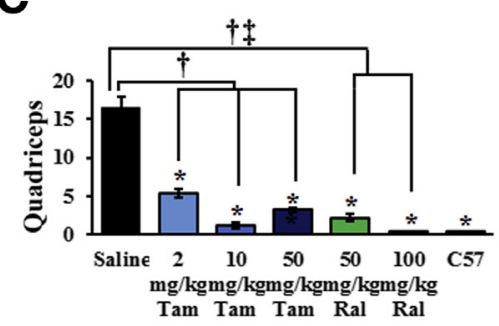

F

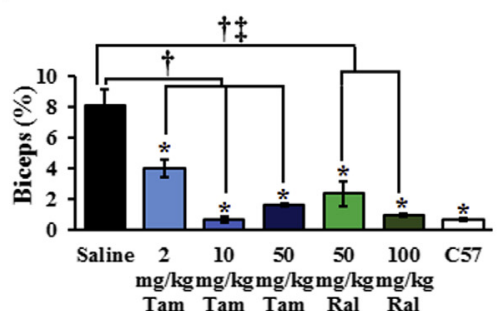

D

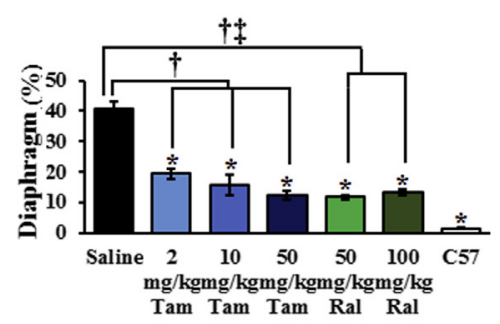

G

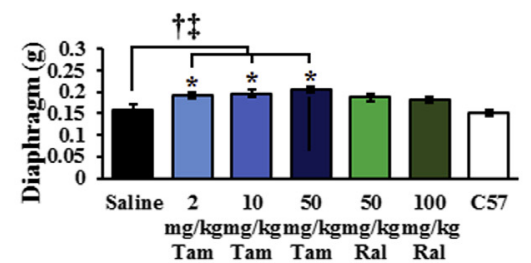

Figure 4 Effect of 1-year treatment of tamoxifen (Tam) and raloxifene (Ral) on muscle fibrosis. A: Masson's trichrome staining of tibialis anterior (TA), quadriceps (Quad), diaphragm (Diaph), heart, and biceps. Percentages of collagen accumulation area in TA (B), quadriceps (C), diaphragm (D), heart (E), and biceps (F). G: Diaphragm weights. P448L mice treated with saline only (saline); 2, 10, and $50 \mathrm{mg} / \mathrm{kg} \mathrm{Tam;} \mathrm{and} 50$ and $100 \mathrm{mg} / \mathrm{kg} \mathrm{Ral;}$ and untreated C57 mice (C57). Data are expressed as means \pm SEM $(\mathbf{B}-\mathbf{G}) . n=10$ mice (5 female and 5 male; $\mathbf{B}-\mathbf{G}$ ). ${ }^{*} P<0.05$, two-tailed $t$-test for comparing individual treatment with saline group; ${ }^{\dagger} P<0.05$, one-way analysis of variance test for comparing multiple tamoxifen or raloxifene treatments with saline; ${ }^{\ddagger} P<0.05$, Pearson correlation coefficient test for tamoxifen's or raloxifene's dose dependence.

only moderately reduced the mass of the male reproductive organs, with statistical significance only detected to the vas deferens at $100 \mathrm{mg} / \mathrm{kg}$ (Supplemental Figure S9, A-E).

Both tamoxifen and raloxifene at any dosage showed limited effect on the female reproductive organs, without significant difference compared with the control groups. The only significant change was the increase in the mammary fat pad after the treatment with $50 \mathrm{mg} / \mathrm{kg}$ tamoxifen (Supplemental Figure S9, F-H).
None of the treatments affected the size of the brain (Supplemental Figure S10, A-C). Raloxifene did not show any obvious effect on spleen in male and female mice, whereas $50 \mathrm{mg} / \mathrm{kg}$ tamoxifen significantly increased spleen size in male mice compared with saline group (Supplemental Figure S10, D-G). Histology of the liver and kidney and levels of serum enzymes showed no significant difference among all of the groups (Supplemental Figure S10G and Figure 3E). However, a dramatic 
A

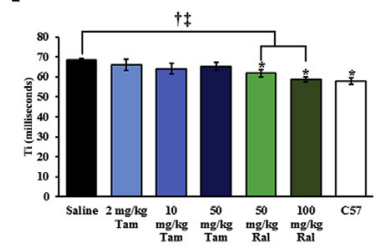

E

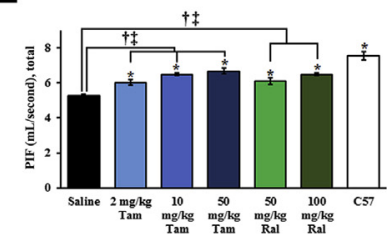

B

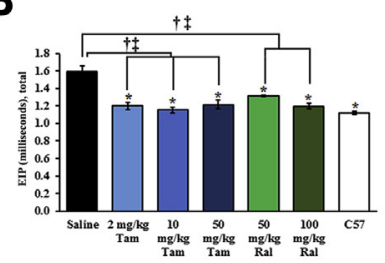

$\mathbf{F}$

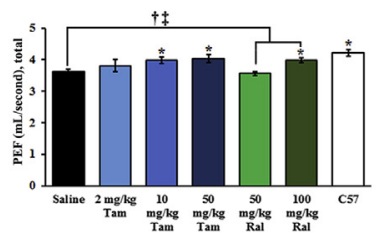

C

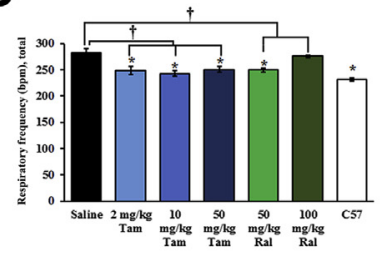

G

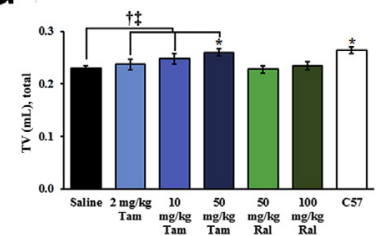

D

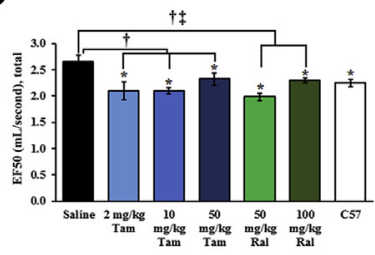

H

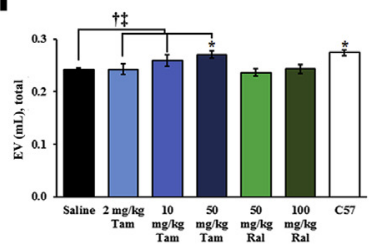

Figure 5 Effects of 1-year treatment of tamoxifen (Tam) and raloxifene (Ral) on respiratory function. A: Inspiratory time (Ti). B: End inspiratory pause (EIP). C: Respiratory frequency. D: Midexpiratory flow (EF50). E: Peak inspiratory flow (PIF). F: Peak expiratory flow (PEF). G: Tidal volume (TV). H: Expired volume (EV). P448L mice treated with saline only (saline); 2, 10, and $50 \mathrm{mg} / \mathrm{kg} \mathrm{Tam;} \mathrm{and} 50$ and $100 \mathrm{mg} / \mathrm{kg}$ Ral; and untreated C57 mice (C57). Data are expressed as means \pm SEM. $n=10$ mice (5 female and 5 male). ${ }^{*} P<0.05$, two-tailed $t$-test for comparing individual treatment with saline group; ${ }^{\dagger} P<0.05$, one-way analysis of variance test for comparing multiple tamoxifen or raloxifene treatments with saline; ${ }^{\ddagger} P<0.05$, Pearson correlation coefficient test for tamoxifen's or raloxifene's dose dependence.

reduction of total bilirubin was observed in the groups treated with $50 \mathrm{mg} / \mathrm{kg}$ tamoxifen and $100 \mathrm{mg} / \mathrm{kg}$ raloxifene. Creatine kinase levels decreased significantly in correlation with alanine transaminase in all treatment groups (Figure 3E).

\section{Discussion}

\section{Mechanism of the Efficacy}

The results from the current study demonstrate the clear efficacy of both the tamoxifen and raloxifene on the FKRP-related dystroglycanopathy. This includes reduced muscle degeneration, significant reduction in muscle fibrosis, and improvement in respiratory and skeletal muscle functions. Therapeutic benefit further includes the improvement in bone density, potentially reducing the risk of fracture, a major threat to patients as disease progresses. The mechanisms for the efficacy are, however, not clearly understood. Decades of investigation have elucidated several pathways by which both tamoxifen and raloxifene alter whole body metabolisms and positively affect progression of many diseases, and these pathways are likely relevant to the outcome observed in the current study. One most significant effect of the SERMs is their
A

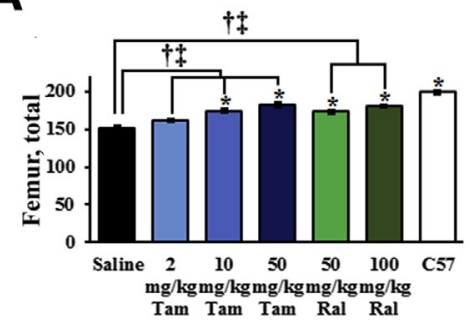

D

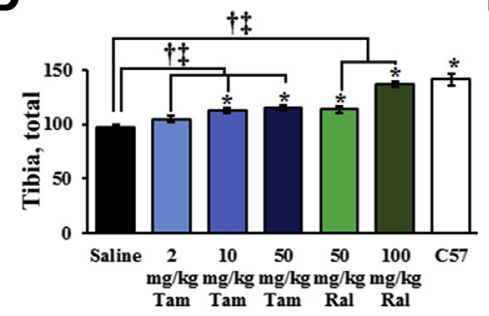

B

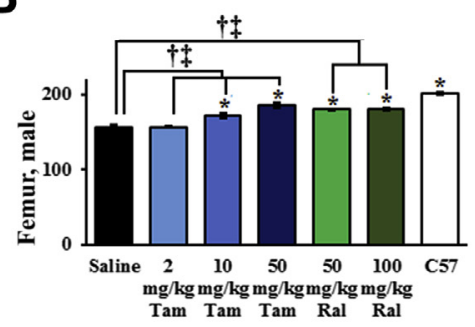

E

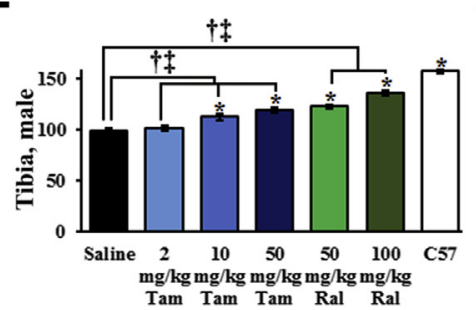

C

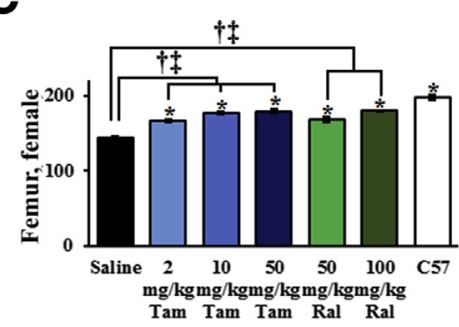

$\mathbf{F}$

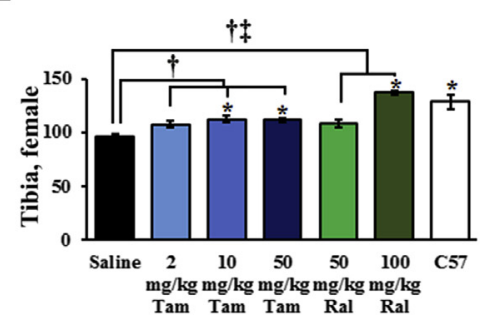

Figure 6 Effect of 1-year treatments of tamoxifen (Tam) and raloxifene (Ral) on bone density in total, female, or male mice. Bone density of femur in total (A), male (B), and female (C) mice and tibia in total (D), male (E), and female (F) mice. $P 448 \mathrm{~L}$ mice treated with saline only (saline); 2,10, and $50 \mathrm{mg} / \mathrm{kg}$ Tam; and 50 and $100 \mathrm{mg} / \mathrm{kg}$ Ral; and untreated C57 mice (C57). Data are expressed as means \pm SEM. $n=10$ mice ( 5 female and 5 male; $\mathbf{A}$ and $\mathbf{D}) ; n=5$ male mice (B and E); $n=$ 5 female mice $(\mathbf{C}$ and $\mathbf{F}) .{ }^{*} P<0.05$, two-tailed $t$-test for comparing individual treatment with saline group; ${ }^{\dagger} P<0.05$, one-way analysis of variance test for comparing multiple tamoxifen or raloxifene treatments with saline; ${ }^{\ddagger} P<0.05$, Pearson correlation coefficient test for tamoxifen's or raloxifene's dose dependence. 
capability to inhibit fibrosis under many conditions. Early study in kidney disease describes the tamoxifen-induced prevention of the extracellular matrix accumulation by decreasing the expression of collagens and fibronectin in association with inhibition of transforming growth factor- $\beta 1$ and plasminogen activator inhibitor- 1 . Tamoxifen is also able to abrogate IL-1 $\beta$ - and angiotensin-II-induced proliferation of fibroblasts. ${ }^{18}$ These effects have led to the use of tamoxifen to ameliorate peritoneal fibrosis. ${ }^{19}$ Tamoxifen has also been demonstrated acting as a potent inhibitor of the transforming growth factor- $\beta$-mediated activation of fibroblasts derived from primary human skin and breast, thus alleviating fibrosis. ${ }^{20}$ Similarly, raloxifene has been reported with antiliver fibrosis effect. ${ }^{21}$ Our results show that one of the most significant changes in the SERM-treated male and female P448L mutant mice is the reduction in fibrosis in all muscle tissues, especially in diaphragm. This is consistent with the report by Dorchies et $\mathrm{al}^{14}$ in dystrophic male $m d x$ mice with tamoxifen treatment. All of the results taken together suggest that the inhibitory effect of the SERMs to fibrosis is likely applicable to a wide range of muscular dystrophies. Reduction of muscle pathology may result from reduced fiber membrane permeability and ion transportation. Anti-inflammatory effect via inhibition of protein kinase $\mathrm{C}$ and NF- $\kappa$ B pathway by the SERMs has been well documented. ${ }^{22}$ These may all play an important role for the reduction of fibrosis and inflammation in the dystrophic muscles. $^{23-25}$

The use of SERMs is expected to affect the fat deposition and body composition. However, the effect of long-term use of SERMs on fat mass in males and on lean muscle tissue mass of both sexes has not been clearly defined. ${ }^{26,27}$ Our study shows that both tamoxifen and raloxifene have profound, yet differential, effect on fat and muscle mass in male and female dystrophic animals. Initial analysis of the treated animal, including both sexes, indicates a significant BW loss with both drugs at all doses examined. However, analysis of treated males and females separately in comparison with the saline-treated same sex control groups shows that the two drugs affect male and female BW differentially. Both drugs have limited effect on BW of the female mice, but cause highly significant reduction in the male mice. This is associated with reduction in the absolute mass of the skeletal muscles, reaching significance with the higher dosages of tamoxifen, but not with raloxifene, in the male mice. Yet again, no significant change in muscle weight is observed in the treated female mice. In contrast, the absolute mass of diaphragm muscle tissues is increased in both male (in the highest dose group) and female (all doses) mice treated with both drugs either significantly or considerably (Supplemental Figure S11). Furthermore, the difference becomes even more significant in the treated male mice when adjusted with greatly reduced BW (Supplemental Figure S12). This is consistent with the observation in the male $m d x$ mice reported by Dorchies et al. ${ }^{14}$ Taken together, the reduced muscle pathology and reduced $\mathrm{BW}$ or relative increase in ratio of muscle mass/BW are likely important for the significant improvement in muscle functions indicated by the treadmill and grip strength performance (Figure 2, D-I). It remains to be determined if the sex-related differential effects are species specific. ${ }^{28}$

\section{Respiratory and Cardiac Functions}

Defects of respiratory and cardiac systems are frequently involved in dystroglycanopathies, and their failures are the common causes behind the lethality of the diseases. Impairment in respiratory function in muscular dystrophies principally stems from the impairment in the chest muscles and critically the diaphragm, which is most severely affected. Both tamoxifen and raloxifene significantly reduce the pathology of the diaphragm, with reduced fibrosis and increased muscle mass. As expected, this results in significant improvement in respiratory function indicated by the dose-dependent increase in peak inspiratory flow and peak expiratory flow, and significant reduction in EIP with the plethysmograph tests. Reduction in EIP is interesting because it reflects a pattern of the breath that has not been described before. Our earlier characterization has identified the extended time of EIP in the P448L mice, significantly different from the wild-type $C 57$ mice. ${ }^{17}$ This is likely the indication of a compensatory effort to overcome the limited capacity of the diseased diaphragm because of extensive fibrosis and loss of muscle mass to achieve desirable inspiratory volume. This may also explain the significant decline in tidal and expired volumes in the mutant mice. Reduced pathology in diaphragm after SERM treatment can maintain normal levels of oxygen supply without the need to deploy such an extra effort. Both drug treatments significantly shortened the EIP and increased tidal and expired volumes for either male or female populations. Overall, improvement in respiratory function constitutes one of the most significant benefits of the treatments.

Treatment with tamoxifen and raloxifene have only limited effect on the cardiac function and no statistical significance can be obtained, probably because of the combination of limited defects in the mutant mice, with only mild fibrosis (maintaining similar $\mathrm{CO}$ to that of wild-type C57 controls), and the limited effect of the treatment. ${ }^{17}$

\section{Drug Preference for Male or Female Patients}

The current results demonstrate that both tamoxifen and raloxifene have significant therapeutic impact on both male and female dystroglycanopathy, with reduced pathology and muscle functions as well as bone density. However, effects of the two drugs distinctive to male and female disease populations require careful consideration for their potential applications in clinics. One of the most striking characteristic feature of the tamoxifen treatment is the significant reduction of BW in male mice, and this is associated with decrease 
(significantly in the $50 \mathrm{mg} / \mathrm{kg}$ group) in absolute skeletal muscle mass when compared with the control. However, the weight ratio between skeletal muscle and BW becomes higher after the treatment, which is likely one of the important factors for the improved muscle functions and reduced muscle damage (Supplemental Figure S12). This would show preference for the use of tamoxifen in the male subjects for treatment of muscular dystrophy, as suggested by the previous study in male $m d x$ mice. ${ }^{14}$ However, tamoxifen treatment diminishes the size of male reproductive organs. This is especially severe for the testicle, vas deferens, and seminal vesicle; all of the structures become severely atrophic or even completely disappear. The other consequence of the tamoxifen treatment is the weakening of abdominal wall (partly related to the reduction in fat deposition), leading to severe hernia in almost all treated male mice (Supplemental Figure S13). In comparison to the tamoxifen treatment, raloxifene treatment in the male population showed an overall less significant reduction in pathology. However, the treatment achieves similar or even better functionality of the skeletal muscles and respiratory system. Most important, raloxifene treatment affects the size of male reproductive organs mildly, and no hernia is observed. These comparisons, therefore, suggest that raloxifene may be preferred over tamoxifen for treating male dystroglycanopathies and muscular dystrophies in general. However, because sex-related differential effects might be species specific and especially adverse effect profile with long-term SERM treatment in men remains to be clarified, results from animal models might only serve to raise our attention for close clinical monitoring of the potential adverse effects. ${ }^{28}$ There is also considerable difference between the two drugs in female population. Highly significant reduction in pathology is achieved with tamoxifen at $10 \mathrm{mg} / \mathrm{kg}$, but similar levels of reduction in pathology is only obtained with 10 times higher dose $(100 \mathrm{mg} / \mathrm{kg})$ of raloxifene. The other significant difference from the early clinic studies with the two drugs is the concern for a higher risk of endometrial cancer with long-term use of tamoxifen, but not with raloxifene. Therefore, one needs to weigh the pros and cons to determine which drug is preferred for treating muscular dystrophies of female population. The wide age range of FKRP-related muscular dystrophy also imposes difficulty for selecting the drugs and dosage.

\section{Dose Relevance to Clinic}

Our results show that both tamoxifen and raloxifene exhibit efficacy in a dose-dependent manner, with the higher dose treatment exhibiting better efficacy in both pathology and functions. Statistical significances for a whole range of histologic and functional benefits are only achieved by 10 and $50 \mathrm{mg} / \mathrm{kg}$ tamoxifen treatment, with the highest dose being most effective. Applying Food and Drug Administration-recommended body surface area-based dosing conversion from mouse to human, with a factor of 12 from the effective $10 \mathrm{mg} / \mathrm{kg}$ in the dystrophic mice, the human equivalent dose would be $50 \mathrm{mg} /$ day for a $60-\mathrm{kg}$ individual patient. ${ }^{29}$ This dosage regimen would, therefore, be not far from that currently used for osteoporosis, cancer prevention, or muscle building. Because $2 \mathrm{mg} / \mathrm{kg}$ treatment (human equivalent dose, approximately $10 \mathrm{mg} / 60 \mathrm{~kg}$ ) is also able to demonstrate some significant improvement in respiratory function and histology in diaphragm and a trend of improvement in cardiac function and other skeletal muscle pathology in the mice, it is perhaps appropriate to start a trial with the currently used 20- to 40-mg daily dosing.

Raloxifene exhibits efficacy at considerably higher dosage than tamoxifen. At $50 \mathrm{mg} / \mathrm{kg}$, raloxifene has demonstrated significant efficacy, including improvement in skeletal muscle and respiratory functions, in both males and females. However, $100 \mathrm{mg} / \mathrm{kg}$ treatment is generally associated with more favorable functional measurements, indicated by the better muscle pathology, especially in diaphragm, and higher degree of normalization in respiratory functions shown by the measurement of EIP and peak inspiratory flow. Benefit to cardiac muscle can also be appreciated with $100 \mathrm{mg} / \mathrm{kg}$ raloxifene regimen, having lowest heart rate and increased $\mathrm{CO}$ index with statistical significance when compared with control group. Applying Food and Drug Administration-recommended body surface calculation, human equivalent dose for raloxifene, based on $100 \mathrm{mg} / \mathrm{kg}$ dosage in mice, would be $500 \mathrm{mg} /$ day for a 60-kg individual. Currently, the standard dose for many applications, including cancer and osteoporosis, in clinics is $60 \mathrm{mg} / \mathrm{day}$, considerably lower than the calculated human equivalent dose. However, higher dosage, such as $120 \mathrm{mg}$ daily, has been trialed, with no additional detrimental effect; thus, it may be the starting point for clinical trials on muscular dystrophy. ${ }^{30}$

\section{Conclusions}

In summary, this study provides strong evidence that tamoxifen and raloxifene can be explored to treat dystroglycanopathy of both sex populations. The mechanisms for the observed therapeutic effect are almost certainly non-disease specific; thus, such treatment approach is likely applicable to muscular dystrophies in general. Our knowledge in long-term use of the drugs in many human conditions with high safety records would permit trials to assess their therapeutic value to muscular dystrophy in clinic with relatively limited safety concern. It needs to be pointed out that this study examined the drugs starting in young mice at early stage of disease progression; further study is required to establish therapeutic potential in disease population at later stages.

\section{Acknowledgments}

B.W. and Q.L.L. conceived and designed the study, acquired and analyzed data, and wrote the manuscript; S.N.S., P.L., L.E.B., and A.B. acquired and interpreted data; 
S.S. and A.D.H. provided reagents; and all authors read and approved the final manuscript.

\section{Supplemental Data}

Supplemental material for this article can be found at https://doi.org/10.1016/j.ajpath.2017.12.011.

\section{References}

1. Beltran-Valero de Bernabe D, Currier S, Steinbrecher A, Celli J, van Beusekom E, van der Zwaag B, Kayserili H, Merlini L, Chitayat D, Dobyns WB, Cormand B, Lehesjoki AE, Cruces J, Voit T, Walsh CA, van Bokhoven H, Brunner HG: Mutations in the O-mannosyltransferase gene POMT1 give rise to the severe neuronal migration disorder WalkerWarburg syndrome. Am J Hum Genet 2002, 71:1033-1043

2. Brown SC, Fassati A, Popplewell L, Page AM, Henry MD, Campbell KP, Dickson G: Dystrophic phenotype induced in vitro by antibody blockade of muscle alpha-dystroglycan-laminin interaction. J Cell Sci 1999, 112(Pt 2):209-216

3. Mercuri E, Brockington M, Straub V, Quijano-Roy S, Yuva Y, Herrmann R, Brown SC, Torelli S, Dubowitz V, Blake DJ, Romero NB, Estournet B, Sewry CA, Guicheney P, Voit T, Muntoni F: Phenotypic spectrum associated with mutations in the fukutin-related protein gene. Ann Neurol 2003, 53:537-542

4. Praissman JL, Willer T, Sheikh MO, Toi A, Chitayat D, Lin YY, Lee H, Stalnaker SH, Wang S, Prabhakar PK, Nelson SF, Stemple DL, Moore SA, Moremen KW, Campbell KP, Wells L: The functional O-mannose glycan on alpha-dystroglycan contains a phospho-ribitol primed for matriglycan addition. Elife 2016, 5. e14473

5. Kanagawa M, Kobayashi K, Tajiri M, Manya H, Kuga A, Yamaguchi Y, Akasaka-Manya K, Furukawa J, Mizuno M, Kawakami H, Shinohara Y, Wada Y, Endo T, Toda T: Identification of a post-translational modification with ribitol-phosphate and its defect in muscular dystrophy. Cell Rep 2016, 14:2209-2223

6. Gerin I, Ury B, Breloy I, Bouchet-Seraphin C, Bolsee J, Halbout M, Graff J, Vertommen D, Muccioli GG, Seta N, Cuisset JM, Dabaj I, Quijano-Roy S, Grahn A, Van Schaftingen E, Bommer GT: ISPD produces CDP-ribitol used by FKTN and FKRP to transfer ribitol phosphate onto alpha-dystroglycan. Nat Commun 2016, 7:11534

7. Muchmore DB: Raloxifene: a selective estrogen receptor modulator (SERM) with multiple target system effects. Oncologist 2000, 5:388-392

8. Ramaswamy B, Shapiro CL: Osteopenia and osteoporosis in women with breast cancer. Semin Oncol 2003, 30:763-775

9. Vaglio A, Palmisano A, Alberici F, Maggiore U, Ferretti S, Cobelli R, Ferrozzi F, Corradi D, Salvarani C, Buzio C: Prednisone versus tamoxifen in patients with idiopathic retroperitoneal fibrosis: an openlabel randomised controlled trial. Lancet 2011, 378:338-346

10. Loureiro J, Sandoval P, del Peso G, Gonzalez-Mateo G, FernandezMillara V, Santamaria B, Bajo MA, Sanchez-Tomero JA, GuerraAzcona G, Selgas R, Lopez-Cabrera M, Aguilera AI: Tamoxifen ameliorates peritoneal membrane damage by blocking mesothelial to mesenchymal transition in peritoneal dialysis. PLoS One 2013, 8:e61165

11. Colon JM, Miranda JD: Tamoxifen: an FDA approved drug with neuroprotective effects for spinal cord injury recovery. Neural Regen Res 2016, 11:1208-1211

12. Zheng $\mathrm{K}$, Chen $\mathrm{M}$, Xiang $\mathrm{Y}$, Ma K, Jin F, Wang X, Wang X, Wang $\mathrm{S}$, Wang Y: Inhibition of herpes simplex virus type 1 entry by chloride channel inhibitors tamoxifen and NPPB. Biochem Biophys Res Commun 2014, 446:990-996
13. Hoffman JR, Ratamess NA: Medical issues associated with anabolic steroid use: are they exaggerated? J Sports Sci Med 2006, 5:182-193

14. Dorchies OM, Reutenauer-Patte J, Dahmane E, Ismail HM, Petermann O, Patthey-Vuadens O, Comyn SA, Gayi E, Piacenza T, Handa RJ, Decosterd LA, Ruegg UT: The anticancer drug tamoxifen counteracts the pathology in a mouse model of duchenne muscular dystrophy. Am J Pathol 2013, 182:485-504

15. Chan YM, Keramaris-Vrantsis E, Lidov HG, Norton JH, Zinchenko N, Gruber HE, Thresher R, Blake DJ, Ashar J, Rosenfeld J, Lu QL: Fukutin-related protein is essential for mouse muscle, brain and eye development and mutation recapitulates the wide clinical spectrums of dystroglycanopathies. Hum Mol Genet 2010, 19:3995-4006

16. Wu B, Shah SN, Lu P, Richardson SM, Bollinger LE, Blaeser A, Madden KL, Sun Y, Luckie TM, Cox MD, Sparks S, Harper AD, Lu QL: Glucocorticoid steroid and alendronate treatment alleviates dystrophic phenotype with enhanced functional glycosylation of alphadystroglycan in mouse model of limb-girdle muscular dystrophy with FKRPP448L mutation. Am J Pathol 2016, 186:1635-1648

17. Blaeser A, Awano H, Wu B, Lu QL: Progressive dystrophic pathology in diaphragm and impairment of cardiac function in FKRP P448L mutant mice. PLoS One 2016, 11:e0164187

18. Delle H, Rocha JR, Cavaglieri RC, Vieira JM Jr, Malheiros DM, Noronha IL: Antifibrotic effect of tamoxifen in a model of progressive renal disease. J Am Soc Nephrol 2012, 23:37-48

19. Huang JW, Yen CJ, Wu HY, Chiang CK, Cheng HT, Lien YC, Hung KY, Tsai TJ: Tamoxifen downregulates connective tissue growth factor to ameliorate peritoneal fibrosis. Blood Purif 2011, 31:252-258

20. Carthy JM, Sundqvist A, Heldin A, van Dam H, Kletsas D, Heldin CH, Moustakas A: Tamoxifen inhibits TGF-beta-mediated activation of myofibroblasts by blocking non-smad signaling through ERK1/2. J Cell Physiol 2015, 230:3084-3092

21. Luo F, Ishigami M, Achiwa K, Ishizu Y, Kuzuya T, Honda T, Hayashi K, Ishikawa T, Katano Y, Goto H: Raloxifene ameliorates liver fibrosis of nonalcoholic steatohepatitis induced by cholinedeficient high-fat diet in ovariectomized mice. Dig Dis Sci 2015, 60: $2730-2739$

22. Jamdade VS, Mundhe NA, Kumar P, Tadla V, Lahkar M: Raloxifene inhibits NF-kB pathway and potentiates anti-tumour activity of cisplatin with simultaneous reduction in its nephrotoxictiy. Pathol Oncol Res 2016, 22:145-153

23. Patel BM, Desai VJ: Beneficial role of tamoxifen in experimentally induced cardiac hypertrophy. Pharmacol Rep 2014, 66:264-272

24. Cho E, Zhang Y, Pruznak A, Kim HM: Effect of tamoxifen on fatty degeneration and atrophy of rotator cuff muscles in chronic rotator cuff tear: an animal model study. J Orthop Res 2015, 33:1846-1853

25. Madaro L, Pelle A, Nicoletti C, Crupi A, Marrocco V, Bossi G, Soddu S, Bouche M: PKC theta ablation improves healing in a mouse model of muscular dystrophy. PLoS One 2012, 7:e31515

26. Sheean PM, Hoskins K, Stolley M: Body composition changes in females treated for breast cancer: a review of the evidence. Breast Cancer Res Treat 2012, 135:663-680

27. Hesselbarth N, Pettinelli C, Gericke M, Berger C, Kunath A, Stumvoll M, Bluher M, Kloting N: Tamoxifen affects glucose and lipid metabolism parameters, causes browning of subcutaneous adipose tissue and transient body composition changes in C57BL/6NTac mice. Biochem Biophys Res Commun 2015, 464:724-729

28. Wibowo E, Pollock PA, Hollis N, Wassersug RJ: Tamoxifen in men: a review of adverse events. Andrology 2016, 4:776-788

29. Nair AB, Jacob S: A simple practice guide for dose conversion between animals and human. J Basic Clin Pharm 2016, 7:27-31

30. Agnusdei D, Iori N: Raloxifene: results from the MORE study. J Musculoskelet Neuronal Interact 2000, 1:127-132 